
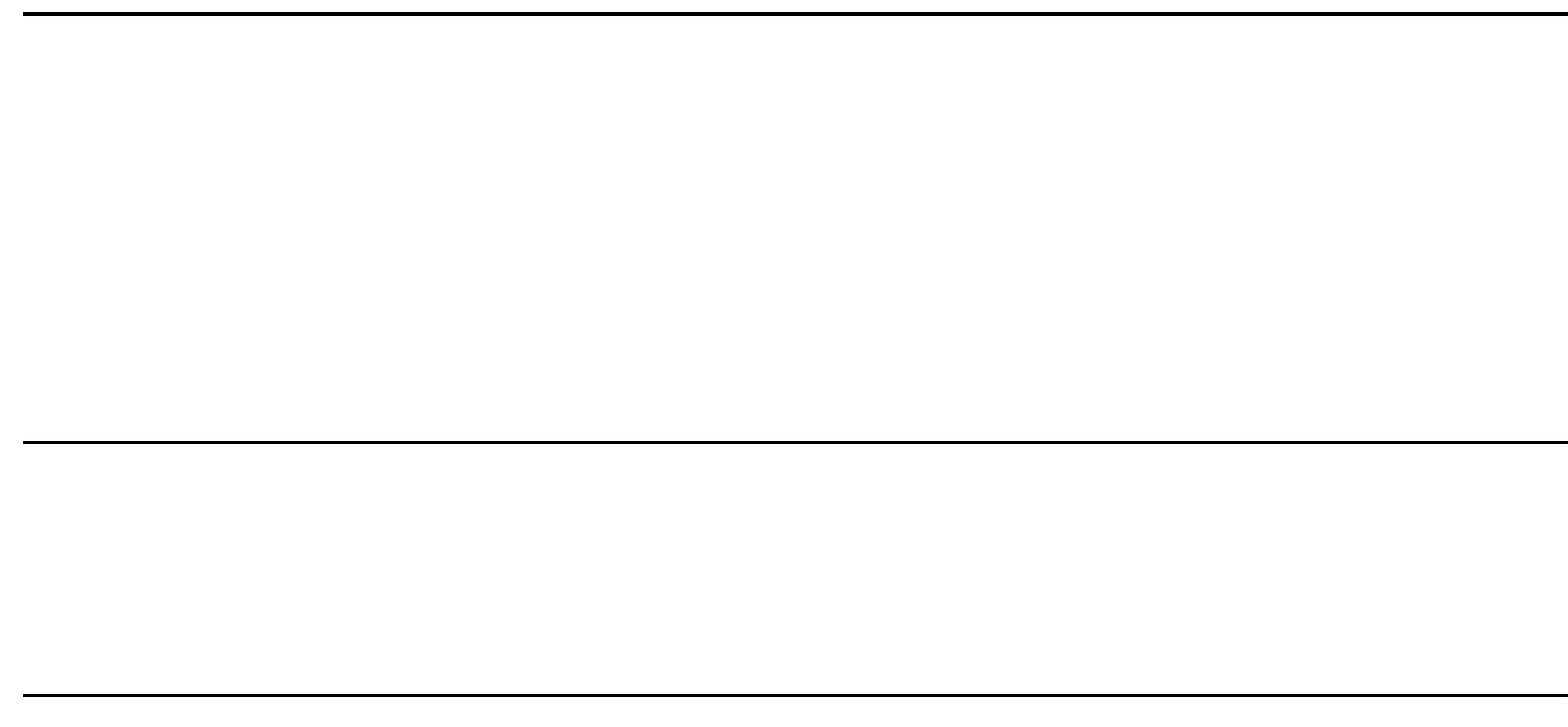


\title{
DSM-5 EATING DISORDERS AMONG ADOLESCENTS AND YOUNG ADULTS IN FINLAND: A PUBLIC HEALTH CONCERN
}

The running title: Prevalence and Incidence of Eating Disorders

\author{
Yasmina Silén, $\mathrm{MD}^{1}$ \\ Pyry N. Sipilä, MD, $\mathrm{PhD}^{1}$ \\ Anu Raevuori MD, $\mathrm{PhD}^{1,2}$ \\ Linda Mustelin, $\mathrm{MD}, \mathrm{PhD}, \mathrm{MPH}^{3}$ \\ Mauri Marttunen, $\mathrm{MD}, \mathrm{PhD}^{2}$ \\ Jaakko Kaprio, MD, $\mathrm{PhD}^{3}$ \\ Anna Keski-Rahkonen, $\mathrm{MD}, \mathrm{PhD}, \mathrm{MPH}^{1}$
}

\footnotetext{
${ }^{1}$ Clinicum, Department of Public Health, University of Helsinki, Finland

${ }^{2}$ Department of Adolescent Psychiatry, University of Helsinki and Helsinki University

Central Hospital, Finland

${ }^{3}$ Department of Public Health \&Institute for Molecular Medicine Finland (FIMM)

University of Helsinki, Finland
}

Address correspondence to:

Yasmina Silén, PO Box 20, Tukholmankatu 8, Biomedicum 2B 5 $5^{\text {th }}$ Floor, 00014 University of Helsinki, Finland e-mail: yasmina.silen@gmail.com

Word count for the manuscript 4,216 and the abstract 244 


\section{Acknowledgments}

2 Yrjö and Tuulikki Ilvonen foundation funded the work. PNS has been supported by the

3 Finnish Foundation for Alcohol Studies and the Helsinki Institute of Life Science.

5 Disclosure of Conflicts

6 The authors declare that they have no conflict of interests.

7

\section{Data availability statement}

9 The data are not publicly available due to privacy or ethical restrictions. We encourage

10 interested researchers to contact us about arrangements for secondary analyses. 


\section{ABSTRACT}

2

3 Objective

4 We aimed to assess the lifetime prevalence, 10-year incidence, and peak periods of onset

5 for eating disorders as defined by the Fifth Diagnostic and Statistical Manual of Mental

6 Disorders (DSM-5) among adolescents and young adults born in the 1980s in Finland.

8 Method

9 Virtually all Finnish twins born in 1983. $87(n=5,600)$ were followed prospectively from

10 the age of 12 years. A subsample of participants $(n=1,347)$ was interviewed using a semi-

11 structured diagnostic interview in their early twenties.

13 Results

14 The prevalence of lifetime DSM-5 eating disorders was $17.9 \%$ for females and $2.4 \%$ for

15 males (pooled across genders, 10.5\%). The estimated lifetime prevalences for females and

16 males, respectively, were $6.2 \%$ and $0.3 \%$ for anorexia nervosa (AN), $2.4 \%$ and $0.16 \%$ for

17 bulimia nervosa (BN), $0.6 \%$ and $0.3 \%$ for binge eating disorder (BED), $4.5 \%$ and $0.16 \%$ for

18 other specified feeding or eating disorder (OSFED), and $4.5 \%$ and $1.6 \%$ for unspecified

19 feeding or eating disorder (UFED). Among females, the prevalence of OSFED

20 subcategories was as follows: atypical AN 2.1\%, purging disorder 1.3\%, BED of low

21 frequency/imited duration $0.7 \%$, and BN of low frequency /imited duration $0.4 \%$. The 10 - 
1 year incidence rate of eating disorders was 1,700 per 100,000 person-years among females

2 (peak age of onset 16-19 years) and 220 per 100,000 person-years among males.

3

4 Discussion

5 Eating disorders are a common public health concern among youth and young adults,

6 affecting one in six females and one in forty males. Adequate screening efforts, prevention,

7 and interventions are urgently needed.

8

9 Keywords: Eating Disorders; Epidemiology; Prevalence; Incidence; Classification;

10 Diagnosis

11

12

13

14

15

16

17

18

19

20

21

22 
INTRODUCTION

3 Many individuals with eating disorders do not receive the help they need. Few are

4 detected in healthcare, and even fewer get adequate treatment (Cachelin \& Striegel-Moore,

5 2006; Hart, Granillo, Jorm, \& Paxton, 2011). The foundation for improving prevention,

6 detection, and treatment of eating disorders is understanding the magnitude of the

7 problem, the spectrum of symptoms, and the age at which the risk in population is the 8 greatest.

10 Reliable community-based estimates of the occurrence of eating disorders are needed

11 because the diagnostic definitions of eating disorders have changed. The Fifth Diagnostic

12 and Statistical Manual of Mental Disorders (DSM-5) addressed several shortcomings

13 observed in the previous editions by expanding the diagnostic definitions of anorexia

14 nervosa $(\mathrm{AN})$ and bulimia nervosa $(\mathrm{BN})$ and by increasing the number of diagnostic

15 categories. First, binge eating disorder (BED) is included as an independent diagnostic

16 entity. A second new category, other specified feeding or eating disorders (OSFED),

17 comprises atypical anorexia nervosa, purging disorder, night eating syndrome, and

18 bulimia nervosa and binge eating disorder of low frequency and/or limited duration. A

19 third new category, unspecified feeding or eating disorder (UFED), is for eating disorders

20 that do not fulfill the criteria of any other eating disorder. In addition, the DSM-IV

21 diagnosis of feeding disorder of infancy or early childhood (FDIEC) was reformulated as

22 avoidant/restrictive food intake disorder (ARFID) and included with pica and rumination 
1 disorder to the Feeding and Eating disorder category in DSM-5. The principal aim of these

2 additions was to increase the clinical utility of the diagnostic system and to ensure that

3 more people with clinically significant eating problems would receive a specific eating

4 disorder diagnosis (American Psychiatric Association, 2013).

6 Studies in the DSM-5 era have shown that the ability of the current classification to capture

7 the clinical features of eating disorders has indeed improved compared to its predecessors

8 (Flament et al., 2015; Mustelin, Lehtokari, \& Keski-Rahkonen, 2016a; Stice, Marti, \& Rohde,

9 2013). Since the introduction of DSM-5, many community-based studies have assessed the

10 occurrence of DSM-5 defined eating disorders (Galmiche, Dechelotte, Lambert, \&

11 Tavolacci, 2019; Glazer et al., 2019; Lindvall Dahlgren, Wisting, \& Ro, 2017; Mitchison et

12 al., 2019; Udo \& Grilo, 2018; Wagner et al., 2017). Still, gaps in knowledge remain.

14 Discrepancies exist in the prevalence estimates for individual diagnoses and all eating

15 disorders, likely due to methodological differences such as varying sample characteristics,

16 study designs, and assessment methods (Lindvall Dahlgren \& Wisting, 2016; Lindvall

17 Dahlgren et al., 2017; Mitchison \& Hay, 2014). This highlights the need for well-conducted

18 population-based studies with large sample sizes that use diagnostic interviews (Udo \&

19 Grilo, 2018). Less attention has also been paid to the prevalence of eating disorders among

20 males (Javaras \& Hudson, 2015; Murray et al., 2017). Few studies have assessed the

21 prevalence of OSFED, and even fewer have investigated the prevalence and

22 manifestations of UFED (Javaras \& Hudson, 2015). Finally, information about the 
1 occurrence of new cases, the incidence and age of onset, is vital to the appropriate

2 allocation of resources for the prevention, detection, and treatment of eating disorders.

3 Nonetheless, only a few studies in DSM-5 era have addressed these factors, and those who

4 have, have mostly focused on females (Allen, Byrne, Oddy, \& Crosby, 2013; Micali et al.,

5 2017; Mustelin, Raevuori, Hoek, Kaprio, \& Keski-Rahkonen, 2015; Mustelin et al., 2016a;

6 Mustelin et al., 2016b; Smink, van Hoeken, Oldehinkel, \& Hoek, 2014; Stice et al., 2013;

7 Udo \& Grilo, 2018).

9 To address these needs, we utilized data from a large Finnish nationwide longitudinal

10 twin study that consists of five consecutive birth cohorts born in 1983-87. Using a rigorous

11 protocol, we estimated the lifetime prevalence, 10-year incidence, and peak period of onset

12 for the total number of eating disorders and for the individual diagnostic categories. 


\section{METHODS}

FinnTwin12 Birth Cohorts

4 Participants were part of a population-based longitudinal twin study, FinnTwin12. The

5 study consisted of five consecutive birth cohorts of twins who were born between the

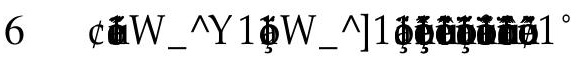

$$
n=5,600
$$

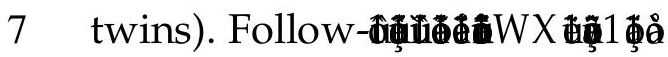

urred at ages

$814,17.5$, and 22 years. Depending on the data collection wave, information was gathered

9 by questionnaires from twins, parents, and teachers. Response rates were $85-90 \%$ across all 10 waves (Kaprio, 2013; Rose et al., 2019). Figure 1 shows the study participation flowchart.

Intensively-studied sample

13 A nested subset of twins was selected from the epidemiological sample for a more

14 intensive assessment. For inclusion in the intensively-studied sample, at least one parent

15 had to be Finnish speaking, and parents had to return the family questionnaire and had to

16 permit school contact. The intensively-studied sample consisted of 1,035 families, the

17 majority of whom were selected at random (72.3\%, 748 families). Because major funding

18 for the FinnTwin12 Study was obtained from the National Institute on Alcohol Abuse and

19 Alcoholism (NIAAA) in the US, the rest of the subsample (27.7\%, 287 families) were

20 selected based on parental self-reports (elevated scores on the Malmö-modified Michigan

21 Alcoholism Screening Test, Mm-MAST), indicating a risk of alcohol problems. This was

22 done to enrich the sample with families who could inform on familial factors and origins 
1 of alcohol use. The study protocol has been described more thoroughly previously (Rose,

2 Dick, Viken, Pulkkinen, \& Kaprio, 2004).

4 Data collection and analysis were carried out in accordance with the Declaration of

5 Helsinki. It was approved by the ethics committee of the Department of Public Health at

6 the University of Helsinki and the Institutional Review Board of Indiana University.

$7 \quad$ Written informed consent was provided by all participants.

9 Measurements and diagnostic interview for eating disorders

11 In the fourth follow-up, in 2006-2009, when the twins were approximately 22 years old

12 (range 21-26 years, mean age 22.4 years, standard deviation 0.7), 638 men and 709 women

13 from the intensively studied sample (total $n=1,347,73 \%$ of the target sample, 620 complete

14 twin pairs) attended a clinical interview. The interview was conducted by trained

15 interviewers who had a degree in healthcare (registered nurses, advanced graduate

16 students in psychology, and masters of health care). The interview staff was

17 initially trained at the Indiana University Medical School with follow-up training in

18 Finland. Most of the interviews were conducted face-to-face $(n=709)$ and the rest by

19 phone using Structured Clinical Interview for DSM-IV (SCID) (First, M. B., Spitzer, R. L.,

20 Gibbon, M., \& Williams, J. B, 2002) which has been used previously for eating disorders

21 with an excellent interrater agreement (Mustelin et al., 2016b). During the interview,

22 participants were questioned in detail about their eating behaviors, compensatory habits, 
1 and potential cognitive distortions related to food, weight, and body image, applying the

2 DSM-IV criteria. Further, participants were asked to elaborate on the time course of

3 symptoms, detection in healthcare, and any treatment they had received. Interviewers

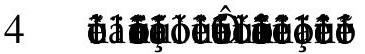

5 measured or self-reported in interviews conducted by phone. Based on this information,

6 the body mass index was calculated as body mass ( $\mathrm{kg}$ ) divided by height $(\mathrm{m})$ squared.

7 Participants were also asked in detail about their weight history. Based on this

8 information, a weight history diagram was drawn, which included a narrative explanation

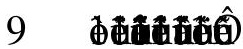

11 Validation of DSM-5 eating disorder diagnoses

12 Based on the answers, interviewers categorized participants into three groups. The first

13 group fulfilled the DSM-IV criteria for AN or BN. The second group showed signs of

14 eating disorder symptoms or attitudes (i.e. cognitive distortions about weight or body

15 image, fear of weight gain, dieting, fasting, purging, laxative or other misuses of drugs to

16 control weight, excessive exercise, unhealthy behaviors related to drive for muscularity,

17 bingeing, and weight loss). The third group did not report such behaviors. Three medical

18 doctors (YS, AR, AK), highly experienced in the diagnosis and treatment of eating

19 disorders, established consensus DSM-5 diagnoses for all participants in the first and

20 second groups $(\mathrm{n}=196)$. The recoding was made using all the relevant data in the case

21 notes and by examining the weight history diagram. Table 1 summarizes the diagnostic

22 criteria that we used to diagnose eating disorders. 
1 Diagnoses were given in a hierarchic order: AN trumped BN; $A N, B N$, and BED trumped

2 OSFED, and all other specified eating disorders trumped UFED. A diagnosis of OSFED or

3 UFED was given only to those who had never had AN, BN, or BED. The diagnostic

4 crossover was challenging to interpret, and we identified only three participants with AN 5 who progressed to BN.

7 As the interview questions were based on DSM-IV classifications, to which substantial

8 changes have been made in the DSM-5, some key questions were missing. For example,

9 questions for binge eating specifiers such as disgust or eating alone or marked distress

10 were not available. However, in most cases, the interviewers had written detailed

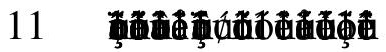

12 diagram, and these were used when we sought consensus for DSM-5 diagnoses.

13 Nevertheless, we were not able to assess pica, rumination, avoidant/restrictive food intake

14 disorder, or night eating syndrome, because the diagnostic interview lacked specific

15 questions for these. Further, we did not have the tools to assess the impairment related to 16 the diagnosis.

18 The residual diagnosis UFED was given to participants reporting eating disorder

19 symptoms that caused distress comparable to levels we have observed clinically but did

20 not meet the criteria for any specified diagnosis. To investigate the whole spectrum of

21 eating disorders in the community and to better understand constituents of the residual

22 UFED category, we divided it into four subcategories. We named the subcategories as 
1 follows: UFED restrictive syndrome, UFED BN/BED, UFED other, and UFED insufficient

2 information. The symptom criteria for each subcategory are described in detail in Table 1. 3

4 Statistical analysis

5 We assessed the lifetime prevalence and ten-year incidence rate for specified and

6 unspecified DSM-5 eating disorders. Incidence rates were calculated from the age of 10 to

7 20. We conducted Pearson chi, squared tests for cross-tabulations. All confidence intervals 8 and p-values were adjusted for the sampling of twins within twin pairs. All analyses were 9 performed using statistical software Stata 13. 
RESULTS

\section{DISTRIBUTION}

4 Of the 1,347 participants (709 females, 638 males), 142 (10.5\%) were diagnosed with a

5 DSM-5 eating disorder. Eating disorders were more common in females with a sex ratio of

6 8:1. Of the 709 females, 127 (17.9\%) were diagnosed with a DSM-5 eating disorder, but of

7 the 638 males, only 15 (2.4\%) were diagnosed with a DSM-5 eating disorder. Three

8 participants (two females, one male) gained two diagnoses. In 15 twin pairs (9

9 monozygotic), both twins were diagnosed with a DSM-5 eating disorder. One pair was

10 males, and the rest were females. Figure 2 shows the diagnostic distributions of eating

11 disorders among females and males.

\section{LIFETIME PREVALENCE}

\section{Females}

15 The combined lifetime eating disorder prevalence was $17.9 \%$ for females. The lifetime

16 prevalence estimates of specified eating disorders were $6.2 \%$ for $\mathrm{AN}, 2.4 \%$ for $\mathrm{BN}$, and

$170.6 \%$ for BED. When the analyses were restricted to those whose minimum body mass

18 index (BMI) was $17.5 \mathrm{~kg} / \mathrm{m}^{2}$ or lower, the lifetime prevalence of $\mathrm{AN}$ fell to $4.7 \%$. In terms of

19 severity (American Psychiatric Association, 2013), 11\% of those with anorexia nervosa had

20 extreme AN $\left(\mathrm{BMI}<15 \mathrm{~kg} / \mathrm{m}^{2}\right), 20 \%$ severe AN (BMI 15. $\left.15.99 \mathrm{~kg} / \mathrm{m}^{2}\right), 11 \%$ moderate AN

21 (BMI 16. $\left.16.99 \mathrm{~kg} / \mathrm{m}^{2}\right)$ and most (57\%) had a mild form of the disorder (BMI 17.00. 18.5

$\left.22 \mathrm{~kg} / \mathrm{m}^{2}\right)$. 
1 Among females, the total lifetime prevalence for OSFED was $4.5 \%$ and, more specifically,

$22.1 \%$ for atypical AN, 1.3\% for purging disorder, $0.4 \%$ for BN (low frequency /imited

3 duration), and $0.7 \%$ for BED (low frequency /imited duration). The total lifetime

4 prevalence for UFED was $4.5 \%$ and, more specifically, $1.4 \%$ for the restrictive syndrome,

$5 \quad 1.7 \%$ for subthreshold BN/BED, $1.1 \%$ for other, and $0.3 \%$ for insufficient information

6 (Table 2).

$8 \quad$ Males

9 The combined lifetime eating disorder prevalence was $2.4 \%$ for males. The lifetime

10 prevalence estimates of AN was $0.3 \%$, BN $0.16 \%$, and BED $0.3 \%$ among men. When the

11 analyses were restricted to those whose minimum BMI was $17.5 \mathrm{~kg} / \mathrm{m}^{2}$ or lower, the

12 prevalence of AN fell to $0.16 \%$.

14 Among males, the total lifetime prevalence for atypical AN based on one diagnosed case

15 was $0.16 \%$, and no other cases of any other specified feeding or eating disorder subtype

16 were found. The total lifetime prevalence for UFED was $1.6 \%$, more specifically, $0.5 \%$ for

17 the restrictive syndrome, $0.5 \%$ for subthreshold $\mathrm{BN} / \mathrm{BED}$, and $0.6 \%$ for other, while no

18 cases with insufficient information were seen (Table 2).

19

20 Prevalences in the enriched and randomly selected groups

21 In sensitivity analyses, we compared the lifetime prevalence of eating disorders between

22 the sample enriched for families with a high risk of alcohol problems and the randomly 
1 selected sample. The total eating disorder prevalence was similar among females in the

2 enriched sample (15.6\% [95\% CI 10.8-22]) and the randomly selected sample (18.7\% [95\%

3 CI 15.4-22.5]), $\mathrm{p}$ for difference $\varangle 0.37$. The same was true among males in the enriched

4 sample (3.8\% [95\% CI 1.6-8.5]) and the randomly selected sample (1.8\% [95\% CI 0.9-3.5], p

5 for difference $\varangle$.16. The supplement table 1 shows the lifetime prevalence for each

6 diagnosis in enriched and in randomly selected samples.

INCIDENCE

9

10 The incidence rate of eating disorders between 10 and 20 years of age was 1,700 (95\% CI

11 1,400-2,060) per 100,000 person, years among females and 220 (95\% CI 130-410) per 100,000

12 person, years among males. The 10-year incidence rate for each diagnosis for both genders

13 is shown in Table 3.

\section{PEAK AGE OF ONSET}

16

17 For females, there was a steady increase in the onset of DSM-5 eating disorders from age

1812 onwards, and the peak period dated to ages 16.19 years. Figure 3 shows the peak age of

19 onset for the total number of eating disorders, each specific eating disorder, and OSFED

20 and UFED.

21 
1 For males, there were two apparent peaks around early and late adolescence. Because of

2 the small number of cases, only the peak age of onset for overall eating disorders is shown 3 in Figure 3.

4

5

6

7

8

9

10

11

12

13

14

15

16

17

18

19

20

21

22 


\section{DISCUSSION}

3 Our results show that eating disorders, as defined by DSM-5, are highly prevalent. More

4 than 1 in 6 females received a lifetime diagnosis of an eating disorder. In particular,

5 anorexia nervosa (AN) and other forms of restrictive eating disorders were more common

6 than previously reported: 1 in 10 females had suffered from them by the time they reached

7 young adulthood. As expected, we observed significant gender differences in eating

8 disorder presentations: $2.4 \%$ of males received a lifetime diagnosis of an eating disorder

9 (male-female ratio 1:8). Among males, the most common diagnosis was unspecified

10 feeding or eating disorder (UFED). This indicates that the specified diagnostic categories

11 in DSM-5 still do not fully capture the nature of disordered eating in males.

Unexpectedly high prevalence of AN among females

15 We found that $6.2 \%$ of females in this study fulfilled diagnostic criteria for DSM-5 AN. We

16 compared this prevalence estimate to a previously studied Finnish twin cohort of young

17 women (Mustelin et al., 2016b). The study used a two-stage sampling design, and the

18 screen missed some cases. To approximate the prevalence we would have obtained if all

19 individuals in the cohort had been interviewed, we used sampling weights for the

20 randomly sampled screen-negative women to account for the false negatives missed by

21 the symptom screening. Consequently, the AN prevalence among women in the FinnTwin

2216 study rose from $3.6 \%$ to $6.3 \%$, which is almost identical to our current results. 
2 What could explain the high prevalence of AN? First, we studied twins. Previously,

3 multiple births (twins and triplets) have been shown to be an independent risk factor for

4 AN with a hazard ratio of 1.33, but not for other eating disorders (Goodman, Heshmati,

5 Malki, \& Koupil, 2014). Taking this into account, the resulting lifetime prevalence of AN

6 among females in our sample would be $4.7 \%$, which is still high. Moreover, when we

7 excluded those females from our analyses whose co-twin also had an eating disorder, the

8 AN prevalence remained $5.1 \%$.

10 A second factor that could explain the high prevalence of AN is that almost one-third of all

11 females in our sample had a minimum BMI under $18.5 \mathrm{~kg} / \mathrm{m}^{2}$. As notable variations in

12 body weight have been observed across developed countries (Lazzeri et al., 2014), it might

13 be that the BMI threshold of $18.5 \mathrm{~kg} / \mathrm{m}^{2}$ recommended to the diagnosis of DSM-5 AN may

14 be too high for our population. However, when the analyses were restricted to those

15 females whose minimum BMI was $17.5 \mathrm{~kg} / \mathrm{m}^{2}$ or less, our observed lifetime prevalence of

$164.7 \%$ for AN was still higher than previously reported lifetime prevalences (Fairweather-

17 Schmidt \& Wade, 2014; Glazer et al., 2019; Micali et al., 2017; Mohler-Kuo, Schnyder,

18 Dermota, Wei, \& Milos, 2016; Munn-Chernoff et al., 2015; Smink et al., 2014; Stice et al.,

19 2013; Udo \& Grilo, 2018).

21 Third, our research might have over-diagnosed AN, as diagnoses in community studies

22 do not automatically result in clinical cases in real life. We did not have specific tools to 
1 assess impairment relating to eating disorders, but we had some indirect indicators of

2 illness severity. Of females diagnosed with AN in our study, 55\% reported that healthcare

3 professionals had also diagnosed them with an eating disorder in real life. If we only

4 included detected females to the analyses, the lifetime prevalence of AN would still be $53.4 \%$.

7 As eating disorder expressions differ by continent (Hoek, 2016), the socio-cultural climate

8 in Finland may partially explain our high prevalence of AN and atypical AN. Drive to

9 thinness, restrictive eating, and excessive exercise may be culturally favored over

10 bingeing. Indeed, a previous Finnish study conducted in the DSM-IV era showed that

11 anorexia-type eating disorders were common among adolescent females as the lifetime

12 prevalence was $2.6 \%$ for $\mathrm{AN}$ and $7.7 \%$ for $\mathrm{AN}$ not otherwise specified (Isomaa, Isomaa,

13 Marttunen, Kaltiala-Heino, \& Björkqvist 2009).

15 Further, prevalence estimates are influenced by study setting, methods of case detection

16 (screening, self-report, diagnostic interviews), and even by factors related to the type of

17 interview, interview instrument, and experience of the interviewer (Davis, Couper, Janz,

18 Caldwell, \& Resnicow, 2010; Hoek, 2016; Lindvall Dahlgren et al., 2017; Mitchison \& Hay,

19 2014; Thornton, Russell, \& Hudson, 1998). Sometimes methodological issues, such as the

20 low sensitivity of the screening instrument, may lead to underestimation of AN

21 occurrence (Solmi, Hotopf, Hatch, Treasure, \& Micali, 2016). Our research setup was

22 probably good for detecting $\mathrm{AN}$ as a large number of individuals were interviewed by 
1 health-care professionals without relying on screens. More, additional information was

2 gained from detailed weight histories collected through the interviews, and diagnoses

3 were validated by medical doctors.

5 Recently, two studies based on the same UK cohort used a rigorous eating disorder

6 assessment protocol that yielded a higher AN estimate than previously reported (Micali et

$7 \quad$ al., 2015; Micali et al., 2017). Among middle-aged women, the lifetime prevalence of DSM-

85 defined AN was 3.6\%, and among 14- and 16-year-old girls, the point prevalence of AN

9 was $3.2 \%$ and $2.4 \%$, respectively. In these studies, health-care professionals interviewed a

10 large sample of women, and self-reports and parental questionnaires were used to identify

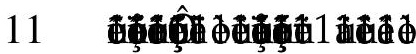

1214 were identified solely based on parental reporting. Further, among middle-aged

13 women, no interview skip rules were used, and the study's two-phase sampling

14 procedure was taken account by using sampling weights. Together, with our research,

15 these results emphasize the importance of a thorough AN assessment in community-based 16 studies.

Distribution of other eating disorders

20 Only $0.6 \%$ of females and $0.3 \%$ of males were diagnosed with BED, which is modest

21 compared to previously found lifetime prevalence estimates (Cossrow et al., 2016;

22 Fairweather-Schmidt \& Wade, 2014; Glazer et al., 2019; Hudson, Coit, Lalonde, \& Pope, 
1 2012; Micali et al., 2017; Smink et al., 2014; Stice et al., 2013; Udo \& Grilo, 2018). Due to the

2 absence of interview questions concerning the distress criterion and binge eating

3 specifiers, we depended on the narrative case notes made by the interviewers. We were

4 conservative in giving the BED diagnosis, and if the information was insufficient for the

5 specific diagnosis, we gave UFED BN/BED diagnosis or no diagnosis at all. Perhaps if

6 diagnostically specific questions had been asked, more of those in the UFED BN/BED

7 group might have received a BED diagnosis.

9 We also found that many individuals in the population experience eating disorders that

10 do not fit the specified diagnostic criteria, as almost two-thirds of all eating disorders

11 detected in males and one-quarter in females belonged to the residual UFED category.

12 Further, our division of UFED into subcategories emphasized the heterogeneous

13 representations of residual eating disorders in the population, adding to previous studies

14 (Hay et al., 2017; Mitchison et al., 2019; Mustelin et al., 2016a; Wade \& O'Shea, 2015).

15 Notably, the definition for UFED is, in many ways, problematic and leaves a lot of room

16 for clinical judgment. We diagnosed UFED when we observed disordered eating that

17 caused distress or impairment that was comparable to levels we have observed clinically,

18 excluding individuals qualifying for another specific eating disorder diagnosis. In practice,

19 the line between normal and pathological eating behavior is challenging to draw as we

20 still do not have an agreed-on definition of what minimally constitutes an eating disorder.

21 Moreover, the evidence regarding the severity of UFED is still mixed (Ekeroth, Clinton,

22 Norring, \& Birgegard, 2013; Hay et al., 2017; Mitchison et al., 2019; Mustelin et al., 2016a; 
1 Wade \& O'Shea, 2015). Nevertheless, the size of the residual category in the population

2 demands that more emphasis should be placed on its identification, research, and targeted

3 treatments.

5 UFED was the most common diagnosis among males in our study. This indicates that the

6 specified diagnostic categories in DSM-5 still do not fully capture the nature of disordered

7 eating in males. Overall, men are more muscular, and weight gain accumulates to different

8 parts of the body than among women, reflecting different genetic predispositions by sex.

9 Thus, weight and shape concerns tend to differ by gender as a simultaneous desire for

10 weight loss (to decrease fat mass) and weight gain (to increase lean muscle mass), and

11 extremely excessive exercise are common features among men (Limbers, Cohen, \& Gray,

12 2018; Raevuori, Keski-Rahkonen, \& Hoek, 2014). In our sample, approximately one-third

13 of males diagnosed with an eating disorder engaged in bingeing, and more than two-fifths

14 reported excessive exercise, concerns in muscularity, or sports-related weight-control

15 behaviors. Therefore, in clinical settings and future studies among boys and men, these

16 behaviors should be recognized to avoid gender-biased under- or misdiagnosis.

18 Total occurrence of eating disorders

20 The sum of different eating disorders in our sample amounted to a prevalence of $17.9 \%$

21 among females. The incidence rate of DSM-5 eating disorders among females aged 10 to 20

22 was also high in our setting, 1,700 per 100,000 person-years, and the risk of eating 
1 disorders started to increase from age 12 onwards. Our prevalence estimate is consistent

2 with other well-conducted community-based studies that have diagnostically interviewed

3 a large sample of females. Approximately 13\% of US-based adolescents and young women

4 (Stice et al., 2013), 15\% of Australian adolescent twins (Fairweather-Schmidt \& Wade, 2014;

5 Wade \& O'Shea, 2015), and 15\% among middle-aged British women (Micali et al., 2017)

6 had suffered from eating disorder during their lifetime. In addition, when we summed up

7 previously published lifetime prevalence estimates from our other cohort (FinnTwin 16)

8 using sampling weights, the total lifetime prevalence for females rose to $14.2 \%$ (Mustelin

9 et al., 2015; Mustelin et al., 2016a; Mustelin et al., 2016b, our calculations). Further, a

10 number of studies have reported high point prevalences of DSM-5 defined eating

11 disorders (10.1\% to 32.9\%) for females (Allen et al., 2013; Flament et al., 2015; Micali et al.,

12 2015; Mitchison et al., 2019; Solmi et al., 2016).

14 Among males, our combined eating disorder lifetime prevalence of $2.4 \%$ was at the high

15 end of previously published lifetime estimates. Yet, four studies among male adolescents

16 and young adults have reported even higher point prevalences of full-threshold and

17 subthreshold eating disorders (2.9\% to $12.8 \%$ ) in DSM-5 era (Allen et al., 2013; Flament et

18 al., 2015; Micali et al., 2015; Mitchison et al., 2019). This means that our estimates of period

19 prevalence may be conservative. Further, some studies that have assessed point

20 prevalence for both genders either using interviews or self-reports, have detected high

21 prevalences up to 22.2\% (Flament et al., 2015; Hammerle, Huss, Ernst, \& Burger, 2016;

22 Hay, Girosi, \& Mond, 2015; Micali et al., 2015; Mitchison et al., 2019; Solmi et al., 2016). 
1 Our study also offers the first estimate of the incidence of eating disorders among males in

2 the DSM-5 era; the incidence rate was 220 per 100,000 person-years from the age of 10 to

3 20. As the risk of eating disorders started to increase in early adolescence, also among

4 males, our study strengthens the evidence that primary prevention efforts should occur at

5 pre-adolescence (Javaras et al., 2015).

7 In contrast to the many studies supporting our findings, three thorough studies using

8 diagnostic interviews have reported more modest lifetime prevalence estimates for eating

9 disorders. In a large national sample of US adults, the lifetime prevalence of specified

10 eating disorders (sum of $\mathrm{AN}, \mathrm{BN}, \mathrm{BED}$ ) was $3.1 \%$ for women and $0.62 \%$ for men (Udo \&

11 Grilo, 2018). Further, in Netherlands and Austria, the lifetime prevalence of eating

12 disorders was 5.7\% and 5.5\% for adolescent girls and $1.2 \%$ and $0.6 \%$ for adolescent boys,

13 respectively (Smink et al., 2014; Wagner et al., 2017). The differences to our results may be

14 partly explained by the different ages of the samples, the different methods of case

15 detection, and factors related to the type and implementation of the diagnostic interviews.

17 Strengths and limitations

18 Our study has some limitations that should be considered when interpreting our results.

19 First, twins may share genetic and environmental influences that predispose them to

20 eating disorders, potentially leading to an overestimation of eating disorders in our

21 sample. Yet, when we excluded those twins whose co-twin also had an eating disorder,

22 the total lifetime prevalence stayed at $14 \%$ among females and $2 \%$ among males. Second, a 
1 subsample (27.7\%) of those interviewed were from families at high risk for alcohol

2 problems. Still, our sensitivity analyses showed that the effect of the enrichment was not

3 statistically significant. Nevertheless, both of these factors may have some effect on the

4 representativeness of our sample. Third, the participants were asked about their eating

5 disorder symptoms and weight changes retrospectively, and therefore, recall bias may

6 have affected the responses. Fourth, the diagnostic interviews were conducted both face-

7 to-face and by phone. We did not find differences in eating disorder presentations by

8 interview type, but this does not necessarily mean that no differences exist, as we were not

9 able to interview the same individuals by both interview types (Muskens et al., 2014;

10 Rohde, Lewinsohn, \& Seeley, 1997). Fifth, the SCID interview used was designed to detect

11 DSM-IV diagnoses and has not yet been validated for DSM-5. However, when establishing

12 the DSM-5 diagnoses, we used additional information from the case notes and clear

13 definitions of DSM-5. Last, as the interview data were collected a decade ago, our results

14 do not reflect the latest trends of eating disorder occurrence.

16 The major strength of our study was that we interviewed a large community-based sample

17 of females and males, mostly face-to-face, without relying on a preceding screening stage

18 that would miss some eating disorder cases. Our eating disorder diagnoses were based on

19 a widely used structured diagnostic interview, and all interviewers were healthcare

20 professionals. Finally, all diagnoses were confirmed by a consensus of medical doctors

21 highly experienced in the detection and treatment of eating disorders. These factors

22 increase the rigor of our assessment. Lastly, participation rates have been low in some 
1 previous prevalence studies (Galmiche et al., 2019). Our rate of $73 \%$ of the target sample

2 was reasonably good.

3

$4 \quad$ Implications and conclusion

5

6 In line with other recent community-based studies, our results from females and males

7 born in the 1980s show that eating disorders, as defined by DSM-5, are a significant public

8 health problem in adolescence and early adulthood. Eating disorder symptoms in the

9 community are diverse and are not fully captured by the present diagnostic categories. In

10 particular, individuals with atypical symptoms need more clinical attention, and their

11 symptoms need more research. Timely prevention, detection, and treatment efforts are

12 essential, and their scale should meet the unmet demand.

13

14

15 


\section{References}

Allen, K. L., Byrne, S. M., Oddy, W. H., \& Crosby, R. D. (2013). DSM-IV-TR and DSM-5 eating disorders in adolescents: Prevalence, stability, and psychosocial correlates in a population-based sample of male and female adolescents. Journal of Abnormal Psychology, 122(3), 720-732. doi:10.1037/a0034004 [doi]

American Psychiatric Association. (2013). Diagnostic and statistical manual of mental disorders (Fifth Edition

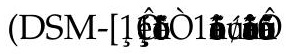

Brown, T. A., Holland, L. A., \& Keel, P. K. (2014). Comparing operational definitions of DSM-5 anorexia nervosa for research contexts. The International Journal of Eating Disorders, 47(1), 76-84. doi:10.1002/eat.22184 [doi]

Cachelin, F. M., \& Striegel-Moore, R. H. (2006). Help seeking and barriers to treatment in a community sample of Mexican American and European American women with eating disorders. The International Journal of Eating Disorders, 39(2), 154-161. doi:10.1002/eat.20213 [doi]

Cossrow, N., Pawaskar, M., Witt, E. A., Ming, E. E., Victor, T. W., Herman, B. K., . . Erder, M. H. (2016). Estimating the prevalence of binge eating disorder in a community sample from the United States: Comparing DSM-IV-TR and DSM-5 criteria. The Journal of Clinical Psychiatry, 77(8), e968-74. doi:10.4088 \CP.15m10059 [doi]

Davis, R. E., Couper, M. P., Janz, N. K., Caldwell, C. H., \& Resnicow, K. (2010). Interviewer effects in public health surveys. Health Education Research, 25(1), 14-26. doi:10.1093/her/cyp046 [doi]

Ekeroth, K., Clinton, D., Norring, C., \& Birgegard, A. (2013). Clinical characteristics and distinctiveness of DSM-5 eating disorder diagnoses: Findings from a large naturalistic clinical database. Journal of Eating Disorders, 1, 31-2974-1-31. eCollection 2013. doi:10.1186/2050-2974-1-31 [doi] 
Fairweather-Schmidt, A. K., \& Wade, T. D. (2014). DSM-5 eating disorders and other specified eating and feeding disorders: Is there a meaningful differentiation? The International Journal of Eating Disorders, 47(5), 524-533. doi:10.1002/eat.22257 [doi]

First, M. B., Spitzer, R. L., Gibbon, M., \& Williams, J. B. (2002). Structured clinical interview for DSM-IV-TR axis I disorders, research version, patient edition. (SCID-I/P). New York: Biometrics Research, New York State Psychiatric Institute

Flament, M. F., Buchholz, A., Henderson, K., Obeid, N., Maras, D., Schubert, N., . . Goldfield, G. (2015). Comparative distribution and validity of DSM-IV and DSM-5 diagnoses of eating disorders in adolescents from the community. European Eating Disorders Review : The Journal of the Eating Disorders Association, 23(2), 100-110. doi:10.1002/erv.2339 [doi]

Galmiche, M., Dechelotte, P., Lambert, G., \& Tavolacci, M. P. (2019). Prevalence of eating disorders over the 2000-2018 period: A systematic literature review. The American Journal of Clinical Nutrition, 109(5), 14021413. doi:10.1093/ajcn/nqy342 [doi]

Glazer, K. B., Sonneville, K. R., Micali, N., Swanson, S. A., Crosby, R., Horton, N. J., . . Field, A. E. (2019). The course of eating disorders involving bingeing and purging among adolescent girls: Prevalence, stability, and transitions. The Journal of Adolescent Health : Official Publication of the Society for Adolescent Medicine, 64(2), 165-171. doi:S1054-139X(18)30438-5 [pii]

Goodman, A., Heshmati, A., Malki, N., \& Koupil, I. (2014). Associations between birth characteristics and eating disorders across the life course: Findings from 2 million males and females born in Sweden, 1975-1998. American Journal of Epidemiology, 179(7), 852-863. doi:10.1093/aje/kwt445 [doi]

Hammerle, F., Huss, M., Ernst, V., \& Burger, A. (2016). Thinking dimensional: Prevalence of DSM-5 early adolescent full syndrome, partial and subthreshold eating disorders in a cross-sectional survey in German schools. BMJ Open, 6(5), e010843-2015-010843. doi:10.1136 bmjopen-2015-010843 [doi] 
Hart, L. M., Granillo, M. T., Jorm, A. F., \& Paxton, S. J. (2011). Unmet need for treatment in the eating disorders: A systematic review of eating disorder specific treatment seeking among community cases. Clinical Psychology Review, 31(5), 727-735. doi:10.1016ðð.cpr.2011.03.004 [doi]

Hay, P., Girosi, F., \& Mond, J. (2015). Prevalence and sociodemographic correlates of DSM-5 eating disorders in the Australian population. Journal of Eating Disorders, 3, 19-015-0056-0. eCollection 2015. doi:10.1186/s40337-015-0056-0 [doi]

Hay, P., Mitchison, D., Collado, A. E. L., Gonzalez-Chica, D. A., Stocks, N., \& Touyz, S. (2017). Burden and health-related quality of life of eating disorders, including avoidant/restrictive food intake disorder (ARFID), in the Australian population. Journal of Eating Disorders, 5, 21-017-0149-z. eCollection 2017. doi:10.1186/s40337-017-0149-z [doi]

Hoek, H. W. (2016). Review of the worldwide epidemiology of eating disorders. Current Opinion in Psychiatry, 29(6), 336-339. doi:10.1097/YCO.0000000000000282 [doi]

Hudson, J. I., Coit, C. E., Lalonde, J. K., \& Pope, H. G.,Jr. (2012). By how much will the proposed new DSM-5 criteria increase the prevalence of binge eating disorder? The International Journal of Eating Disorders, 45(1), 139-141. doi:10.1002/eat.20890 [doi]

Isomaa R., Isomaa AL., Marttunen M., Kaltiala-Heino R., \& Björkqvist K. (2009). The prevalence, incidence and development of eating disorders in Finnish adolescents: a two-step 3-year follow-up study. European Eating Disorder Review, 17(3):199-207. doi:10.1002/erv.919 [doi]

Javaras K.N., Hudson. J. I. (2015). Epidemiology of Eating Disorders. In: Wade T. (eds), Encyclopedia of Feeding and Eating Disorders. Springer, Singapore.

Javaras, K. N., Runfola, C. D., Thornton, L. M., Agerbo, E., Birgegard, A., Norring, C., . . Bulik, C. M. (2015). Sex- and age-specific incidence of healthcare-register-recorded eating disorders in the complete 
Swedish 1979-2001 birth cohort. The International Journal of Eating Disorders, 48(8), 1070-1081.

doi:10.1002/eat.22467 [doi]

Kaprio, J. (2013). The Finnish Twin Cohort study: An update. Twin Research and Human Genetics : The Official Journal of the International Society for Twin Studies, 16(1), 157-162. doi:10.1017 thg.2012.142 [doi]

Lazzeri, G., Rossi, S., Kelly, C., Vereecken, C., Ahluwalia, N., \& Giacchi, M. V. (2014). Trends in thinness prevalence among adolescents in ten European countries and the USA (1998-2006): A cross-sectional survey. Public Health Nutrition, 17(10), 2207-2215. doi:10.1017/\$1368980013002541 [doi]

Limbers, C. A., Cohen, L. A., \& Gray, B. A. (2018). Eating disorders in adolescent and young adult males: Prevalence, diagnosis, and treatment strategies. Adolescent Health, Medicine and Therapeutics, 9, 111-116. doi:10.2147/AHMT.S147480 [doi]

Lindvall Dahlgren, C., \& Wisting, L. (2016). Transitioning from DSM-IV to DSM-5: A systematic review of eating disorder prevalence assessment. The International Journal of Eating Disorders, 49(11), 975-997. doi:10.1002/eat.22596 [doi]

Lindvall Dahlgren, C., Wisting, L., \& Ro, O. (2017). Feeding and eating disorders in the DSM-5 era: A systematic review of prevalence rates in non-clinical male and female samples. Journal of Eating Disorders, 5, 56-017-0186-7. eCollection 2017. doi:10.1186/\$40337-017-0186-7 [doi]

Micali, N., Martini, M. G., Thomas, J. J., Eddy, K. T., Kothari, R., Russell, E., . . Treasure, J. (2017). Lifetime and 12-month prevalence of eating disorders amongst women in mid-life: A population-based study of diagnoses and risk factors. BMC Medicine, 15(1), 12-016-0766-4. doi:10.1186/s12916-016-0766-4 [doi]

Micali, N., Solmi, F., Horton, N. J., Crosby, R. D., Eddy, K. T., Calzo, J. P., . . Field, A. E. (2015). Adolescent eating disorders predict psychiatric, high-risk behaviors and weight outcomes in young adulthood. 
Journal of the American Academy of Child and Adolescent Psychiatry, 54(8), 652-659.e1.

doi:10.1016/j.jaac.2015.05.009 [doi]

Mitchison, D., \& Hay, P. J. (2014). The epidemiology of eating disorders: Genetic, environmental, and societal factors. Clinical Epidemiology, 6, 89-97. doi:10.2147/CLEP.S40841 [doi]

Mitchison, D., Mond, J., Bussey, K., Griffiths, S., Trompeter, N., Lonergan, A., . . Hay, P. (2019). DSM-5 full syndrome, other specified, and unspecified eating disorders in Australian adolescents: Prevalence and clinical significance. Psychological Medicine, , 1-10. doi:10.1017 \$0033291719000898 [doi]

Mohler-Kuo, M., Schnyder, U., Dermota, P., Wei, W., \& Milos, G. (2016). The prevalence, correlates, and help-seeking of eating disorders in Switzerland. Psychological Medicine, 46(13), 2749-2758. doi:10.1017 $\$ 0033291716001136$ [doi]

Munn-Chernoff, M. A., Keel, P. K., Klump, K. L., Grant, J. D., Bucholz, K. K., Madden, P. A., . . Duncan, A. E. (2015). Prevalence of and familial influences on purging disorder in a community sample of female twins. The International Journal of Eating Disorders, 48(6), 601-606. doi:10.1002/eat.22378 [doi]

Murray, S. B., Nagata, J. M., Griffiths, S., Calzo, J. P., Brown, T. A., Mitchison, D., . . Mond, J. M. (2017). The enigma of male eating disorders: A critical review and synthesis. Clinical Psychology Review, 57, 1-11. doi:S0272-7358(17)30137-X [pii]

Muskens, E. M., Lucassen, P., Groenleer, W., van Weel, C., Oude Voshaar, R., \& Speckens, A. (2014). Psychiatric diagnosis by telephone: Is it an opportunity? Social Psychiatry and Psychiatric Epidemiology, 49(10), 1677-1689. doi:10.1007/s00127-014-0861-9 [doi]

Mustelin, L., Lehtokari, V. L., \& Keski-Rahkonen, A. (2016a). Other specified and unspecified feeding or eating disorders among women in the community. The International Journal of Eating Disorders, 49(11), 1010-1017. doi:10.1002/eat.22586 [doi] 
Mustelin, L., Raevuori, A., Hoek, H. W., Kaprio, J., \& Keski-Rahkonen, A. (2015). Incidence and weight trajectories of binge eating disorder among young women in the community. The International Journal of Eating Disorders, 48(8), 1106-1112. doi:10.1002/eat.22409 [doi]

Mustelin, L., Silen, Y., Raevuori, A., Hoek, H. W., Kaprio, J., \& Keski-Rahkonen, A. (2016b). The DSM-5 diagnostic criteria for anorexia nervosa may change its population prevalence and prognostic value. Journal of Psychiatric Research, 77, 85-91. doi:10.1016ð.jpsychires.2016.03.003 [doi]

Raevuori, A., Keski-Rahkonen, A., \& Hoek, H. W. (2014). A review of eating disorders in males. Current Opinion in Psychiatry, 27(6), 426-430. doi:10.1097/YCO.0000000000000113 [doi]

Rohde, P., Lewinsohn, P. M., \& Seeley, J. R. (1997). Comparability of telephone and face-to-face interviews in assessing axis I and II disorders. The American Journal of Psychiatry, 154(11), 1593-1598. doi:10.1176/ajp.154.11.1593 [doi]

Rose, R. J., Dick, D. M., Viken, R. J., Pulkkinen, L., \& Kaprio, J. (2004). Genetic and environmental effects on conduct disorder and alcohol dependence symptoms and their covariation at age 14. Alcoholism, Clinical and Experimental Research, 28(10), 1541-1548. doi:00000374-200410000-00014 [pii]

Rose, R. J., Salvatore, J. E., Aaltonen, S., Barr, P. B., Bogl, L. H., Byers, H. A., . . Kaprio, J. (2019). FinnTwin12 cohort: An updated review. Twin Research and Human Genetics : The Official Journal of the International Society for Twin Studies, 22(5), 302-311. doi:10.1017/hg.2019.83 [doi]

Smink, F. R., van Hoeken, D., \& Hoek, H. W. (2012). Epidemiology of eating disorders: Incidence, prevalence and mortality rates. Current Psychiatry Reports, 14(4), 406-414. doi:10.1007/s11920-012-0282-y [doi]

Smink, F. R., van Hoeken, D., Oldehinkel, A. J., \& Hoek, H. W. (2014). Prevalence and severity of DSM-5 eating disorders in a community cohort of adolescents. The International Journal of Eating Disorders, 47(6), 610-619. doi:10.1002/eat.22316 [doi] 
Solmi, F., Hotopf, M., Hatch, S. L., Treasure, J., \& Micali, N. (2016). Eating disorders in a multi-ethnic innercity UK sample: Prevalence, comorbidity and service use. Social Psychiatry and Psychiatric Epidemiology, 51(3), 369-381. doi:10.1007/s00127-015-1146-7 [doi]

Stice, E., Marti, C. N., \& Rohde, P. (2013). Prevalence, incidence, impairment, and course of the proposed DSM-5 eating disorder diagnoses in an 8-year prospective community study of young women. Journal of Abnormal Psychology, 122(2), 445-457. doi:10.1037/a0030679 [doi]

Sysko, R., Glasofer, D. R., Hildebrandt, T., Klimek, P., Mitchell, J. E., Berg, K. C., . . Walsh, B. T. (2015). The eating disorder assessment for DSM-5 (EDA-5): Development and validation of a structured interview for feeding and eating disorders. The International Journal of Eating Disorders, 48(5), 452-463. doi:10.1002/eat.22388 [doi]

Thornton, C., Russell, J., \& Hudson, J. (1998). Does the composite international diagnostic interview underdiagnose the eating disorders? The International Journal of Eating Disorders, 23(3), 341-345. doi:10.1002/SICI)1098-108X(199804)23:33.0.CO;2-0 [pii]

Trace, S. E., Thornton, L. M., Root, T. L., Mazzeo, S. E., Lichtenstein, P., Pedersen, N. L., \& Bulik, C. M. (2012). Effects of reducing the frequency and duration criteria for binge eating on lifetime prevalence of bulimia nervosa and binge eating disorder: Implications for DSM-5. The International Journal of Eating Disorders, 45(4), 531-536. doi:10.1002/eat.20955 [doi]

Udo, T., \& Grilo, C. M. (2018). Prevalence and correlates of DSM-5-defined eating disorders in a nationally representative sample of U.S. adults. Biological Psychiatry, 84(5), 345-354. doi:S0006-3223(18)31440-9 [pii]

Wade, T. D., \& O'Shea, A. (2015). DSM-5 unspecified feeding and eating disorders in adolescents: What do they look like and are they clinically significant? The International Journal of Eating Disorders, 48(4), 367374. doi:10.1002/eat.22303 [doi] 
Wagner, G., Zeiler, M., Waldherr, K., Philipp, J., Truttmann, S., Dur, W., . . Karwautz, A. F. K. (2017). Mental health problems in Austrian adolescents: A nationwide, two-stage epidemiological study applying DSM-5 criteria. European Child \& Adolescent Psychiatry, 26(12), 1483-1499. doi:10.1007/s00787017-0999-6 [doi] 
Table 1. Diagnostic criteria for DSM-5 eating disorders

\begin{tabular}{c|c}
\hline DIAGNOSIS & DSM-5 DIAGNOSTIC CRITERIA \\
\hline
\end{tabular}

SPECIFIED EATING OR FEEDING DISORDER

\begin{tabular}{|c|c|}
\hline $\begin{array}{c}\text { Anorexia Nervosa } \\
\text { (AN) }\end{array}$ & $\begin{array}{l}\text { A) Restriction of energy intake that resulted in a minimum BMI } \\
\text { (Brown, Holland, \& Keel, 2014; Sysko et al., 2015) } \\
\text { B) Fear of weight gain or of becoming fat, or persistent } \\
\text { behavior that interferes with weight gain even though at a } \\
\text { C) Disturbance in the way body weight or shape is experienced } \\
\text { or denial of the seriousness of the current low body weight } \\
\text { A, B, C criteria need to be fulfilled }\end{array}$ \\
\hline $\begin{array}{c}\text { Bulimia Nervosa } \\
\text { (BN) }\end{array}$ & $\begin{array}{l}\text { Recurrent episodes of binge eating and compensatory behaviors in } \\
\text { order to prevent weight gain at least once a week for more than } \\
\text { three months. With a sense of lack of control over eating during the } \\
\text { episode and self-evaluation is influenced by body shape and weight }\end{array}$ \\
\hline $\begin{array}{l}\text { Binge Eating } \\
\text { Disorder (BED) }\end{array}$ & $\begin{array}{l}\text { Recurrent episodes of binge-eating at least once a week for more } \\
\text { than three months with a sense of lack of control over eating, no } \\
\text { recurrent compensatory behaviors and marked distress, disgust or } \\
\text { embarrassment present regarding binge eating }\end{array}$ \\
\hline
\end{tabular}

OTHER SPECIFIED EATING OR FEEDING DISORDER (OSFED)

\begin{tabular}{c|c}
\hline Atypical Anorexia & All the criteria for AN met, expect despite weight loss minimum \\
Nervosa (OSFED- & BMI is more than $18.5 \mathrm{~kg} / \mathrm{m}^{2}$ \\
Atypical AN) & \\
\hline
\end{tabular}




\begin{tabular}{c|c}
\hline DIAGNOSIS & DSM-5 DIAGNOSTIC CRITERIA \\
low frequency & All the criteria for BN met, but binge-eating and compensatory \\
and /or limited & three months \\
duration (OSFED- & \\
BN) & \\
\hline Binge Eating & Same criteria as in BED, but binge-eating occurs less frequently than \\
Disorder of low & once week or and less than three months \\
frequency and/or & \\
limited duration & \\
(OSFED-BED) & Recurrent purging behavior to influence weight or shape in the \\
\hline Purging Disorder & \\
(OSFED-PD) & absence of binge eating \\
\hline
\end{tabular}

\section{UNSPECIFIED FEEDING OR EATING DISORDER (UFED)}

Clinically significant eating disorder symptoms but do not meet criteria for other specified disorders or insufficient information to make a more specific diagnosis

\begin{tabular}{c|c}
\hline $\begin{array}{c}\text { Restrictive } \\
\text { syndrome }\end{array}$ & $\begin{array}{r}\text { Excessive exercise or fasting or significant weight loss but the } \\
\text { criteria for AN or atypical AN not fulfilled, or weight loss leading to } \\
\text { (UFED-Restrictive) }\end{array}$ \\
\hline Subthreshold & $\begin{array}{r}\text { Objective bingeing behavior with or without compensatory } \\
\text { BN/BED }\end{array}$ \\
behaviors that did not include loss of control, or bingeing that was \\
not restricted to a limited time period or some binge eating \\
specifiers were missing
\end{tabular}




\begin{tabular}{c|c}
\hline DIAGNOSIS & DSM-5 DIAGNOSTIC CRITERIA \\
\hline Other & Eating problems related to depression, or temporary purging, or \\
(UFED-Other) & migh concern and unhealthy behaviors related to a high drive for \\
musculaty
\end{tabular}

Table 2. The lifetime prevalence of DSM-5 eating disorders ( $n=1,347$ comprising 709 females and 638 males)

$\begin{array}{llllll}\text { FEMALES } & 95 \% \mathrm{CI} & \text { MALES } & 95 \% \mathrm{CI} & \text { TOTAL } & 95 \% \mathrm{CI} \\ \%(\mathrm{n}) & \% & \%(\mathrm{n}) & \% & \%(\mathrm{n}) & \%\end{array}$

\section{SPECIFIED EATING OR}

FEEDING DISORDER

\begin{tabular}{lcccccc} 
Anorexia Nervosa & $6.2 \%(44)$ & 4.6 .8 .3 & $0.3 \%(2)$ & $0.08-1.3$ & $3.4 \%(46)$ & 2.5 .4 .6 \\
Anorexia Nervosa (BMI & $4.7 \%(33)$ & 3.3 .6 .6 & $0.16 \%(1)$ & $0.02-1.1$ & $2.5 \%(34)$ & $1.8-3.6$ \\
$\hat{\mathrm{O}}$ & & & & & & \\
\hline Bulimia Nervosa & $2.4 \%(17)$ & $1.5-3.9$ & $0.16 \%(1)$ & $0.02-1.1$ & $1.3 \%(18)$ & $0.8-2.2$ \\
\hline Binge Eating Disorder & $0.6 \%(4)$ & $0.2-1.5$ & $0.3 \%(2)$ & $0.08-1.25$ & $0.4 \%(6)$ & $0.2-1.0$
\end{tabular}

\section{OTHER SPECIFIED EATING}

OR FEEDING DISORDER

(OSFED)

\begin{tabular}{lcccccc} 
OSFED-Atypical AN & $2.1 \%(15)$ & $1.3-3.5$ & $0.16 \%(1)$ & $0.02-1.1$ & $1.2 \%(16)$ & $0.7-2.0$ \\
\hline OSFED-BN & $0.4 \%(3)$ & 0.1 .1 .3 & $0 \%(0)$ & -- & $0.2 \%(3)$ & $0.07-$
\end{tabular}


Table 2. The lifetime prevalence of DSM-5 eating disorders ( $n=1,347$ comprising 709 females and 638 males)

\begin{tabular}{lllllll}
\hline & FEMALES & $95 \% \mathrm{CI}$ & MALES & $95 \% \mathrm{CI}$ & TOTAL & $95 \% \mathrm{CI}$ \\
& $\%(\mathrm{n})$ & $\%$ & $\%(\mathrm{n})$ & $\%$ & $\%(\mathrm{n})$ & $\%$ \\
\hline OSFED-BED & $0.7 \%(5)$ & 0.3 .1 .7 & $0 \%(0)$ & - & $0.4 \%(5)$ & 0.2 .0 .9 \\
\hline Purging Disorder & $1.3 \%(9)$ & $0.7-2.4$ & $0 \%(0)$ & -- & $0.7 \%(9)$ & 0.3 .1 .3 \\
\hline Any OSFED & $4.5 \%(32)$ & $3.2-6.3$ & $0.16 \%(1)$ & $0.02-1.1$ & $2.4 \%(33)$ & $1.8-3.4$
\end{tabular}

UNSPECIFIED FEEDING OR

EATING DISORDER (UFED)

\begin{tabular}{|c|c|c|c|c|c|c|}
\hline Restrictive syndrome & $1.4 \%(10)$ & $0.8-2.6$ & $0.5 \%(3)$ & $0.2-1.5$ & $1.0 \%(13)$ & $0.6-1.7$ \\
\hline Subthreshold BN/BED & $1.7 \%(12)$ & $1.0-3.0$ & $0.5 \%(3)$ & $0.2-1.5$ & $1.1 \%(15)$ & $0.7-1.8$ \\
\hline Other & $1.1 \%(8)$ & $0.6-2.2$ & $0.6 \%(4)$ & $0.2-1.7$ & $0.9 \%(12)$ & $0.5-1.6$ \\
\hline Insufficient information & $0.3 \%(2)$ & $0.07-1.1$ & $0 \%(0)$ & - & $0.15 \%(2)$ & $0.04-$ \\
\hline & & & & & & 0.6 \\
\hline Any UFED & $4.5 \%(32)$ & $3.2-6.3$ & $1.6 \%(10)$ & $0.8-2.9$ & $3.1 \%(42)$ & $2.3-4.2$ \\
\hline ANY EATING OR FEEDING & $17.9 \%$ & $15.1-21.1$ & $2.4 \%(15)$ & $1.4-4.0$ & $10.5 \%$ & $8.9-$ \\
\hline DISORDER & (127) & & & & (142) & 12.4 \\
\hline
\end{tabular}

CI=confidence interval

$\mathrm{n}=$ number of cases

OSFED-Atypical AN = Atypical Anorexia Nervosa

OSFED-BN = Bulimia Nervosa of low frequency and/or limited duration

OSFED-BED = Binge Eating Disorder of low frequency and/or limited duration

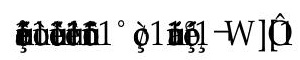

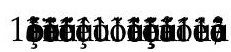


Table 3. The incidence rate of DSM-5 eating disorders between 10 and 20 years of age per 100,000 personyears

$\begin{array}{llllll}\text { FEMALES } & 95 \% \mathrm{CI} & \text { MALES } & 95 \% \mathrm{CI} & \text { TOTAL } & 95 \% \mathrm{CI}\end{array}$

SPECIFIED EATING OR

FEEDING DISORDER

$\begin{array}{lllllll}\text { Anorexia Nervosa } & 580 & 430-810 & 30 & 10-310 & 320 & 230-\end{array}$

440

\begin{tabular}{lcccccc}
\hline Bulimia Nervosa & 180 & $110-340$ & 20 & - & 100 & $60-190$ \\
\hline Binge Eating Disorder & 60 & $20-200$ & 30 & $10-310$ & 40 & $20-120$
\end{tabular}

\section{OTHER SPECIFIED EATING}

OR FEEDING DISORDER

(OSFED)

\begin{tabular}{lcccccc} 
OSFED-Atypical AN & 210 & $130-370$ & 20 & - & 120 & $80-200$ \\
\hline OSFED-BN & 30 & $10-280$ & - & - & 15 & $3-150$ \\
\hline OSFED-BED & 70 & $30-210$ & - & - & 40 & $20-110$ \\
& & & & & & \\
\hline Purging Disorder & 130 & $70-270$ & - & - & 70 & $40-140$ \\
\hline Any OSFED & 440 & $320-640$ & 20 & - & 240 & $170-$
\end{tabular}

\section{UNSPECIFIED FEEDING OR}

EATING DISORDER (UFED)

\begin{tabular}{lcccccc} 
Restrictive syndrome & 130 & $70-270$ & 50 & $10-230$ & 90 & $50-170$ \\
\hline Subthreshold BN/BED & 130 & $70-270$ & 30 & $10-310$ & 80 & $50-160$ \\
& & & & & & \\
\hline Other & 100 & $50-240$ & 60 & $20-220$ & 80 & $50-160$ \\
\hline
\end{tabular}


Table 3. The incidence rate of DSM-5 eating disorders between 10 and 20 years of age per 100,000 personyears

\begin{tabular}{ccccccc}
\hline & FEMALES & $95 \% \mathrm{CI}$ & MALES & $95 \% \mathrm{CI}$ & TOTAL & $95 \% \mathrm{CI}$ \\
& & & & & & \\
& & & & & \\
\hline Insufficient & 10 & - & - & - & 7 & \\
information & & & & & & \\
\hline Any UFED & 370 & $260-550$ & 140 & $80-300$ & 260 & 370 \\
& & & & & & \\
\hline ANY EATING OR FEEDING & 1700 & $1400-$ & 220 & $130-410$ & 980 & $820-$ \\
DISORDER & & 2060 & & & & 1180 \\
\hline
\end{tabular}

CI=confidence interval

$n=$ number of cases

OSFED-Atypical AN = Atypical Anorexia Nervosa

OSFED-BN = Bulimia Nervosa of low frequency and /or limited duration

OSFED-BED = Binge Eating Disorder of low frequency and/or limited duration

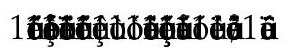


Figure 1. Flowchart of data collection as adapted from (Kaprio, 2013). The intensively studied sample was nested within the epidemiological sample and, therefore, participated in all four questionnaire-based data collection waves. In waves 1, 2, and 4, participants in the intensive study sample took part in additional interviews and tests, as indicated on the right-hand column of the flowchart.

EPIDEMIOLOGICAL SAMPLE

All families with twins born 1983-1987, 5,600 families

WAVE 1, AGE 12

Questionnaires to all twins, parents \& teachers

WAVE 2, AGE 14

Questionnaire to twins and teachers

WAVE 3, AGE 17

Questionnaire to twins

WAVE 4, AGE 22

Questionnaire to twins
INTENSIVELY STUDIED SAMPLE

Target 1,035 families, $72.3 \%$ selected at random

\section{WAVE 1, AGE 12}

Peer assesments at school and parental diagnostic SSAGA interviews $(n=1,860)$

\section{WAVE 2 , AGE 14}

Diagnostic SSAGA interview to twins $(n=1,852)$ neuropsychological tests and saliva hormone assays

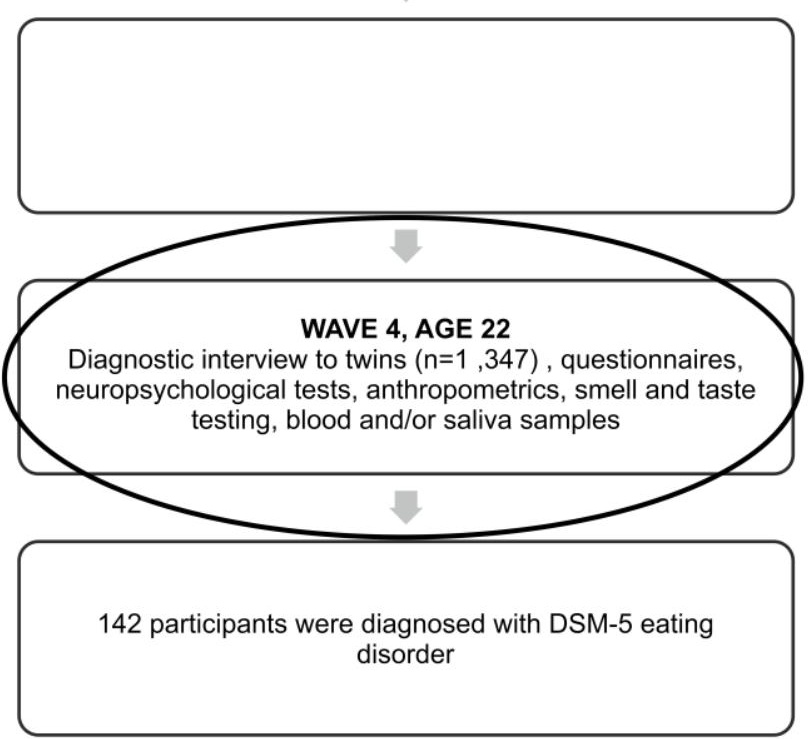


Figure 2. The diagnostic distribution of DSM-5 eating disorders for males and females (\% of all eating disorders in that gender).

MALES FEMALES

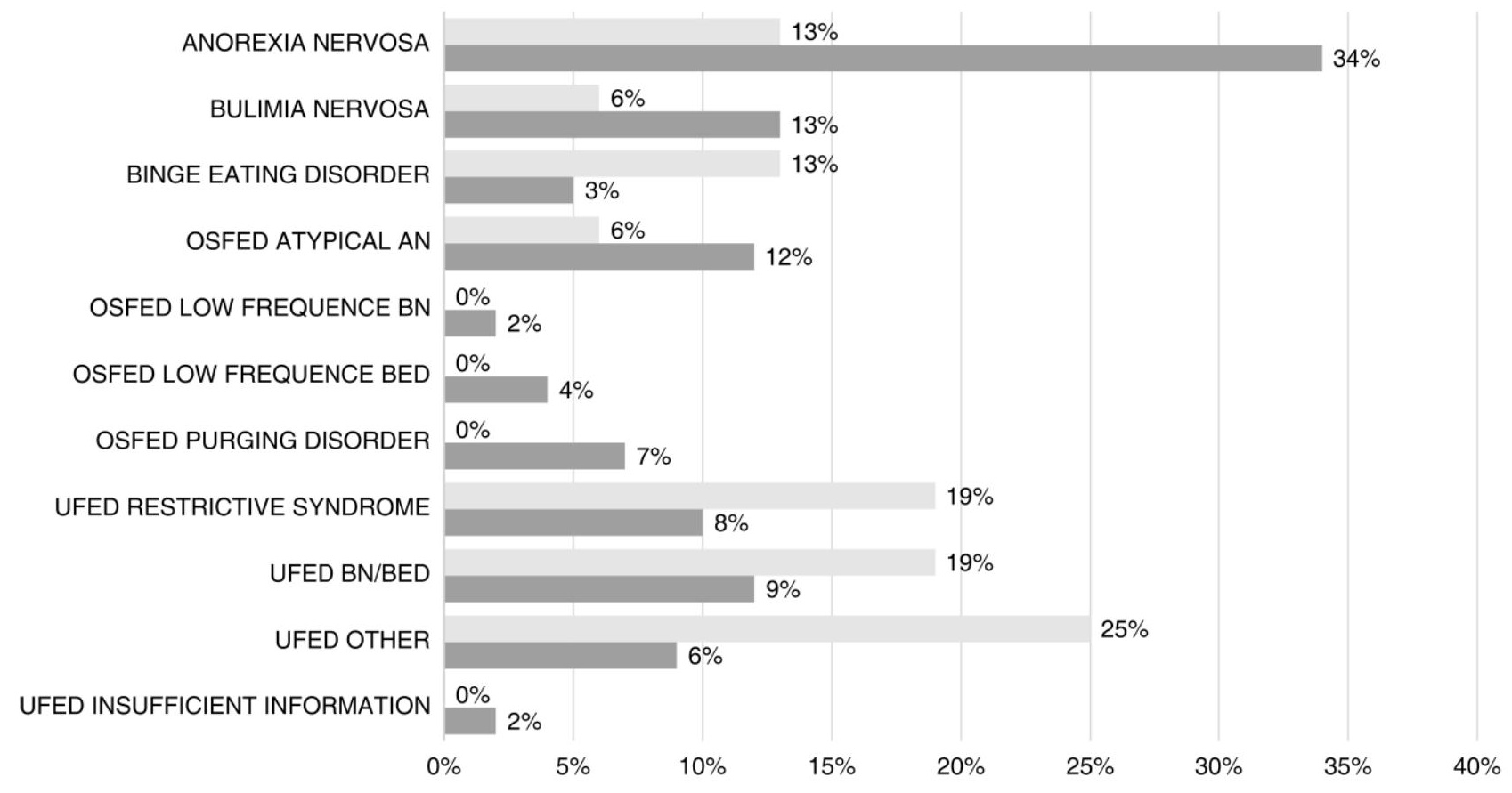


